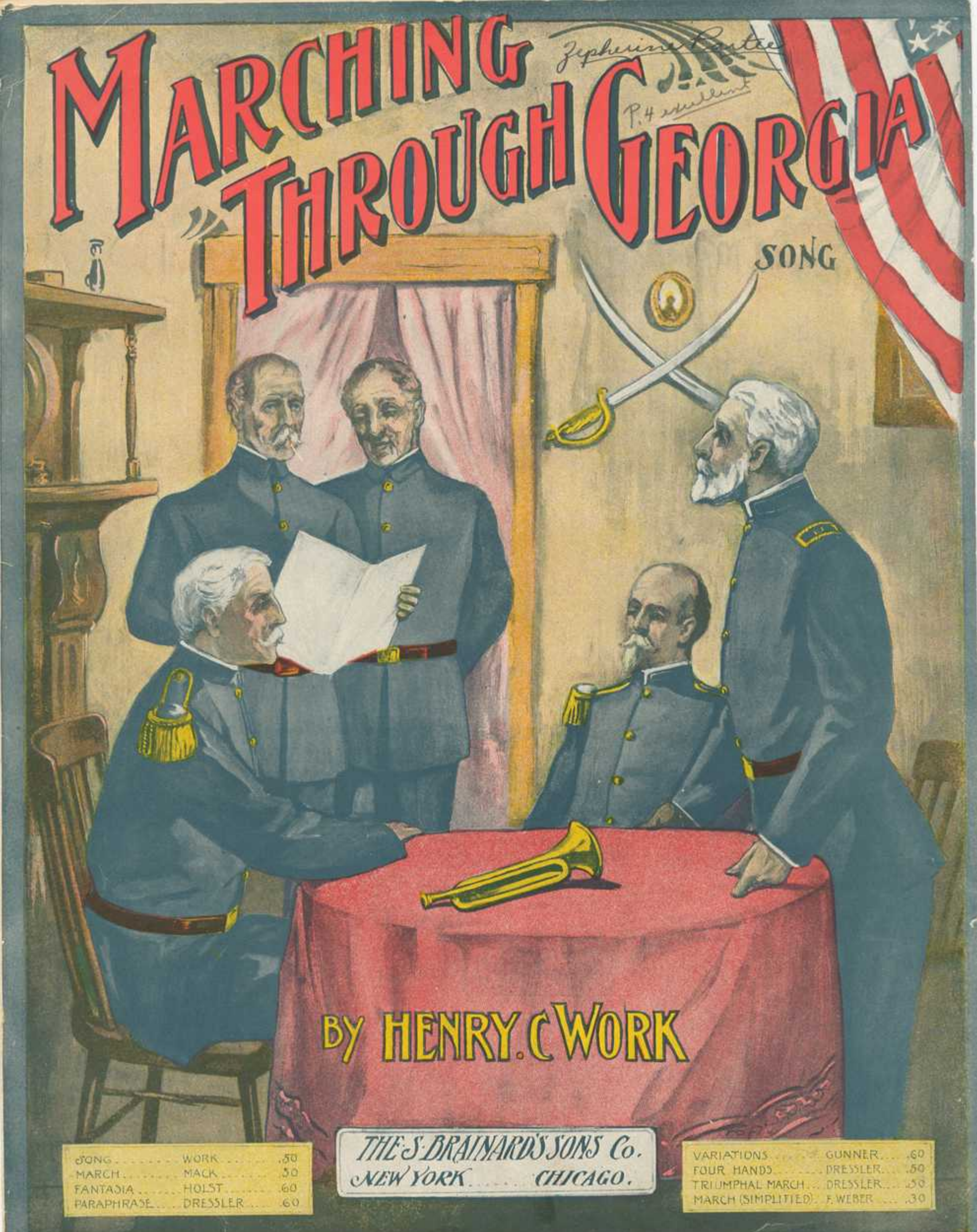


2

\title{
MARCHING THROUGH GEORGIA
}

\author{
GRAND MARCH
}

Edited by Dunean J. Muir

H. C. WORK

Arranged by E. Mack

Tempo di Marcia
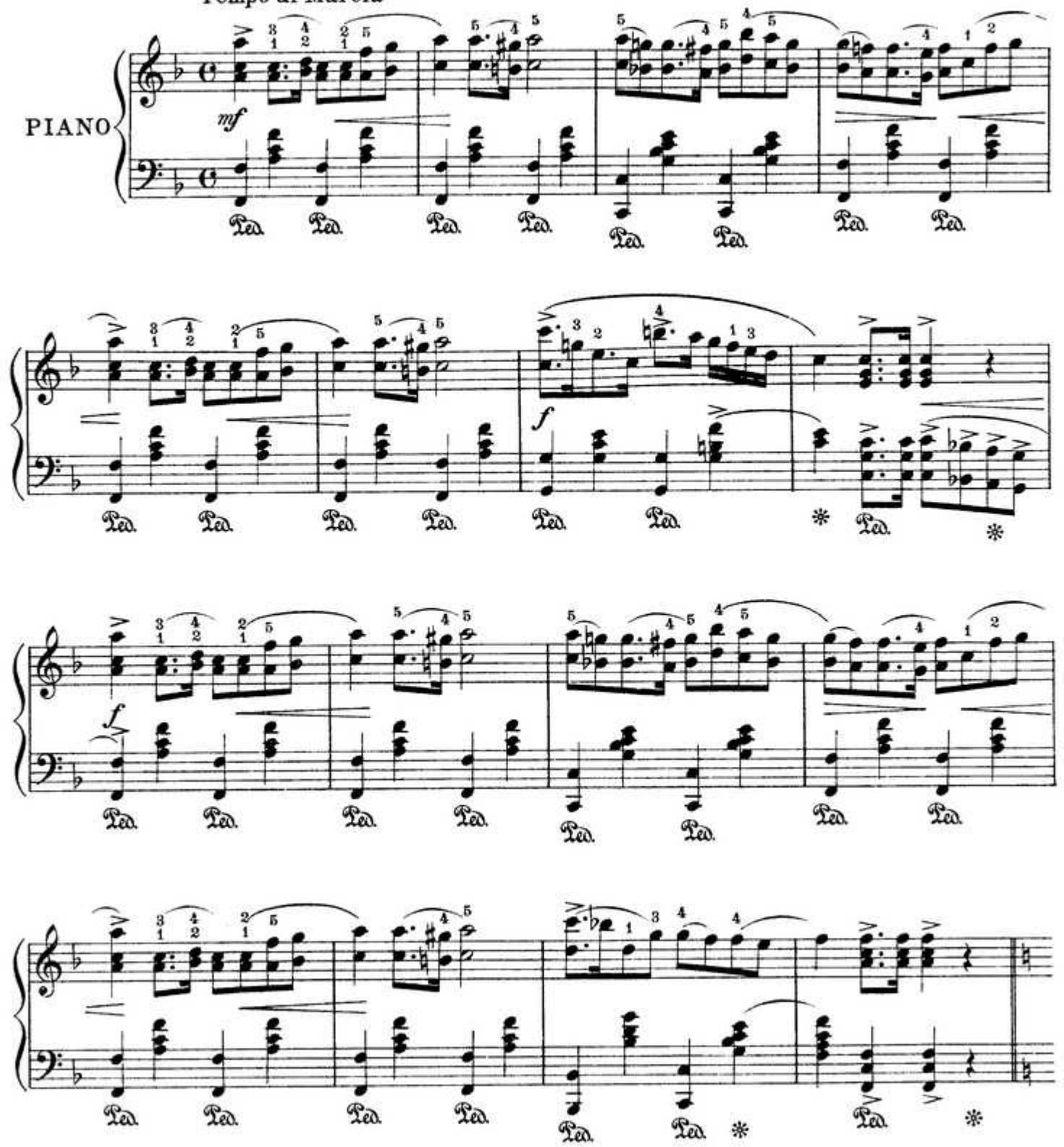

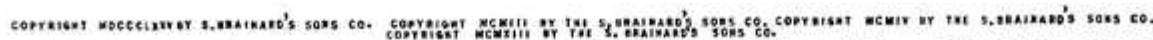

N.B.- The original and only edition of the popular arrangement of "Marching Through Georgia" by E. Mack, is publisbed $18358 \cdot 4$

by The S. Rrainard's Sons Co. 

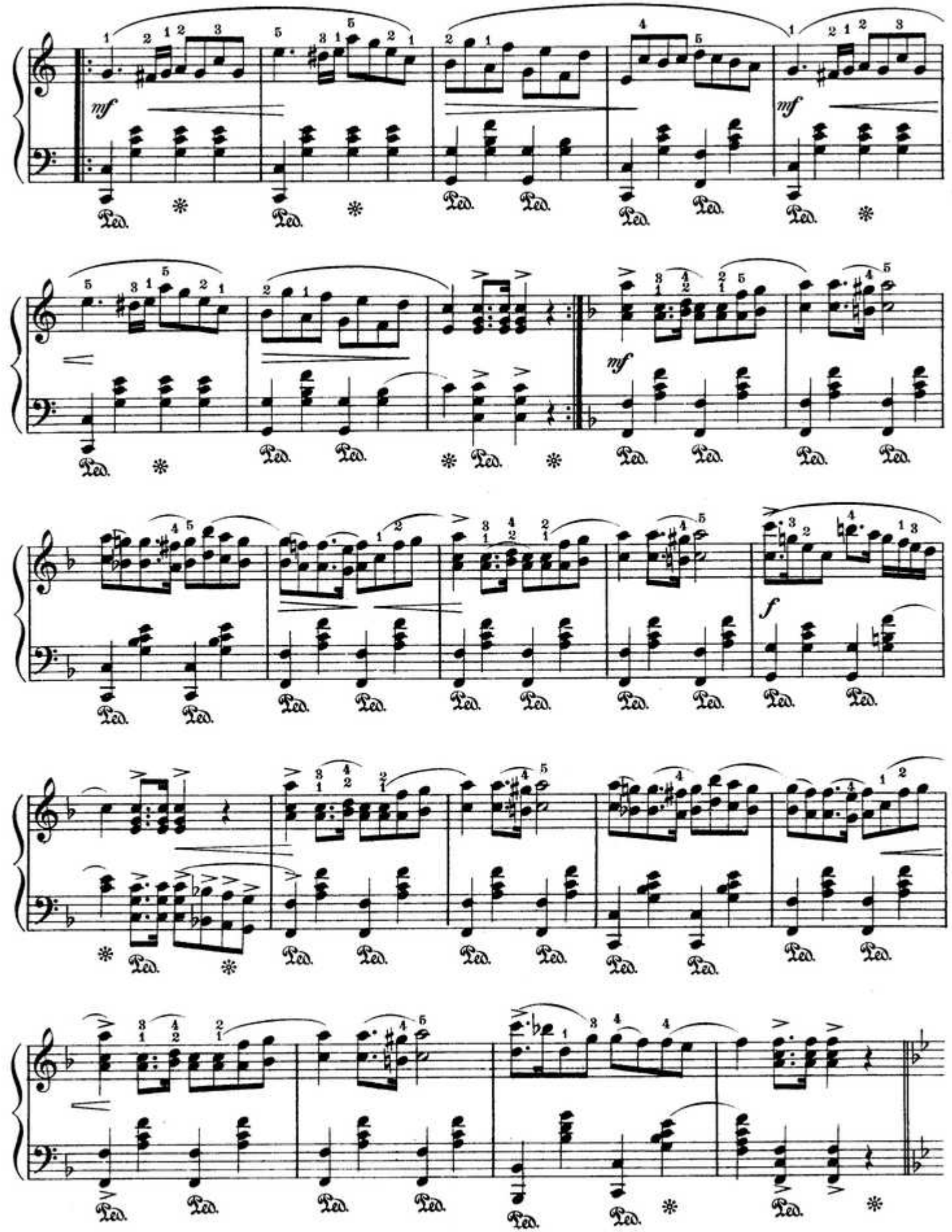

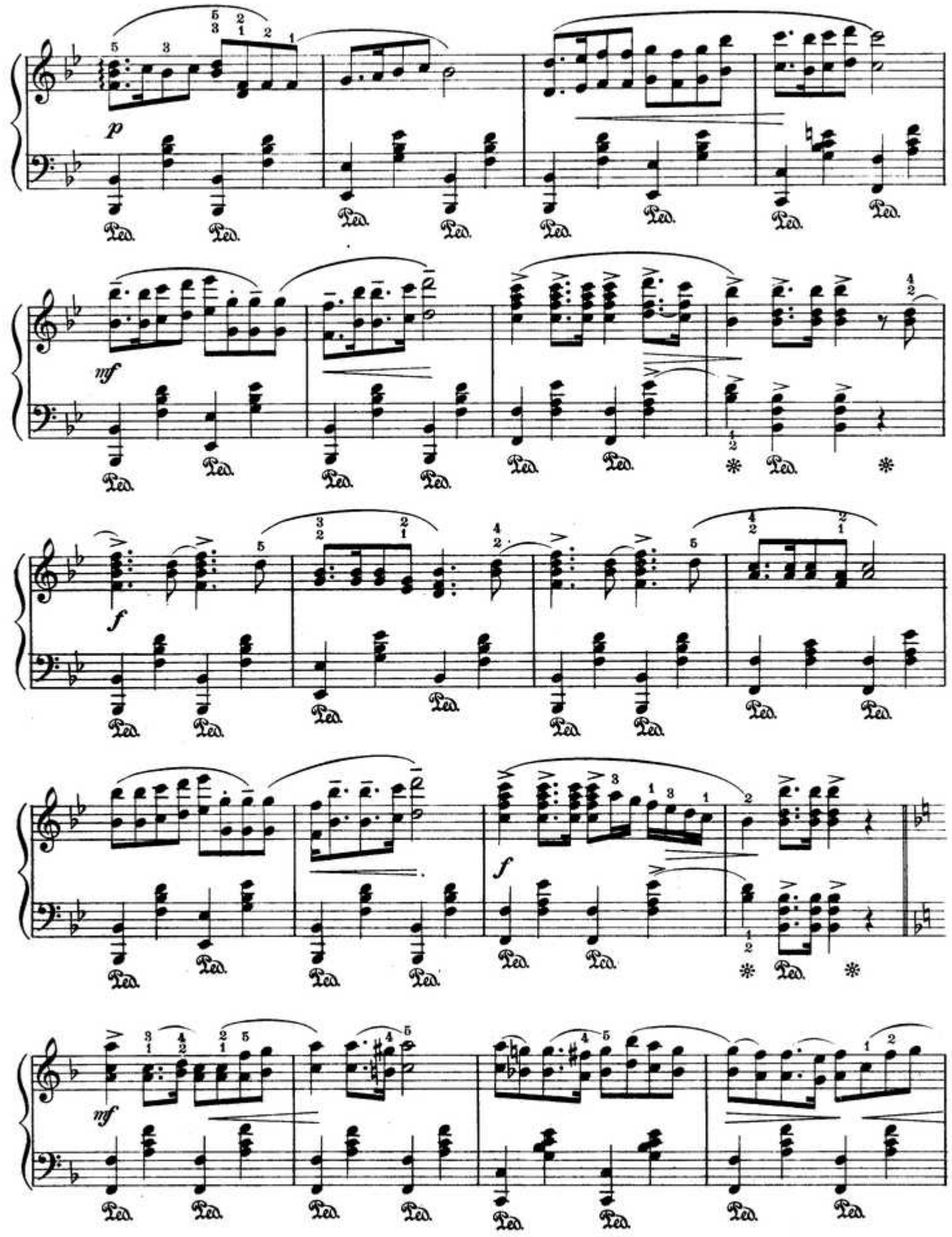

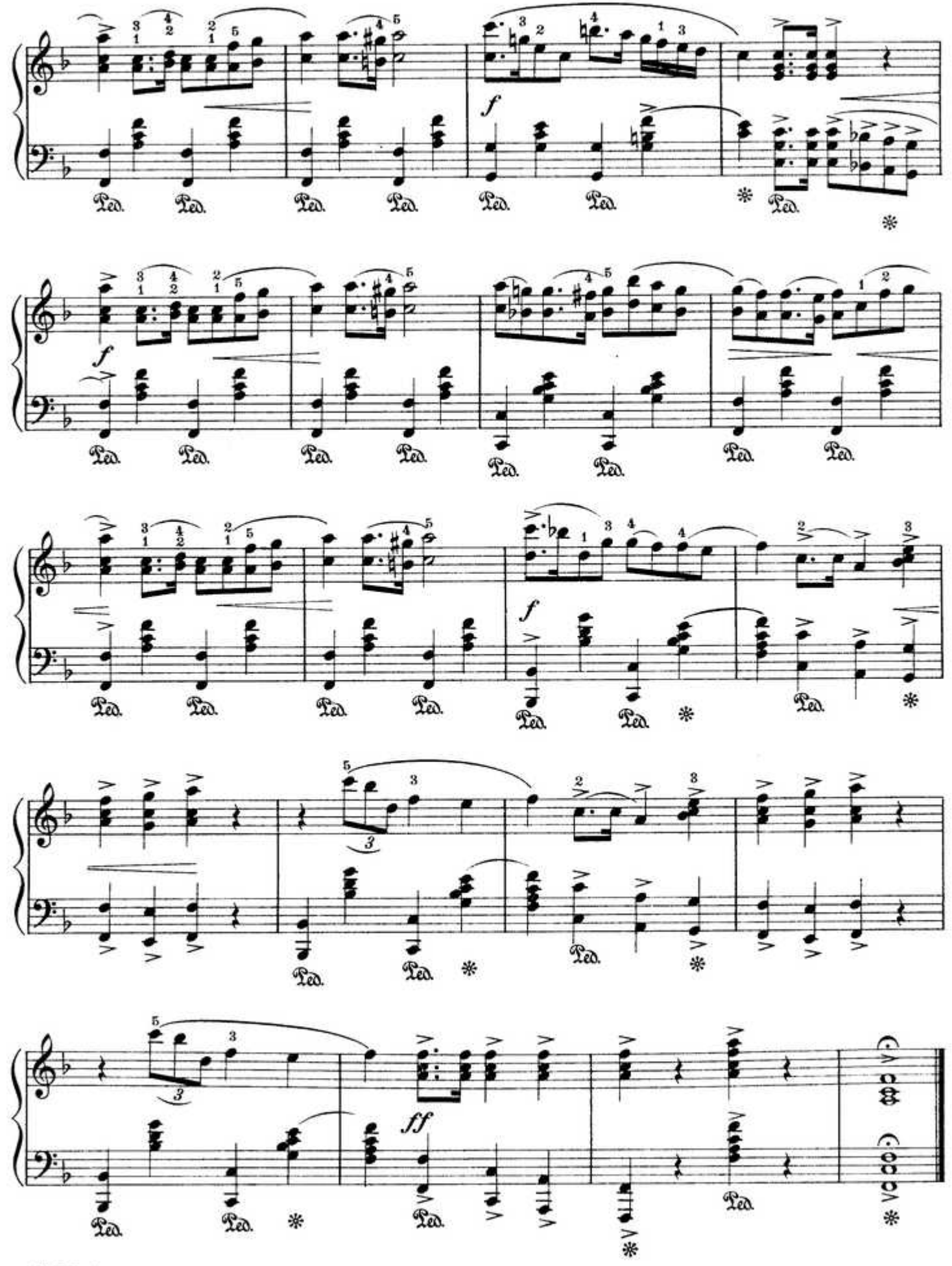

$18358-4$ 


\section{TRY THESE OVER ON YOUR PIANO}

THE SWORD BEARERS .

M A R C H.

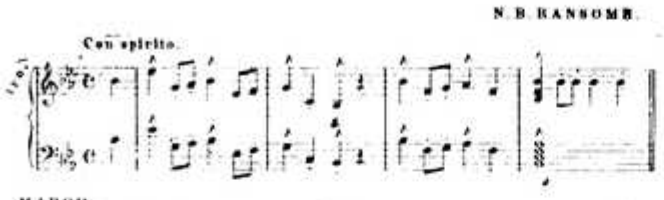

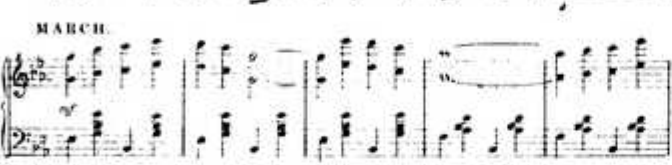

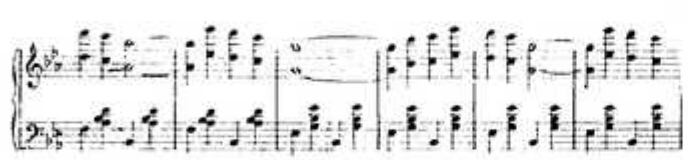

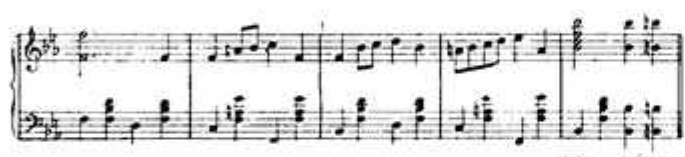

Pr... Sot

GOMMODORE DEWEY'S VIGTORY MARGH.

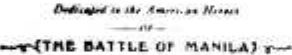

LOVE IN SPRINGTIME.

POLKA BRILLANTE.
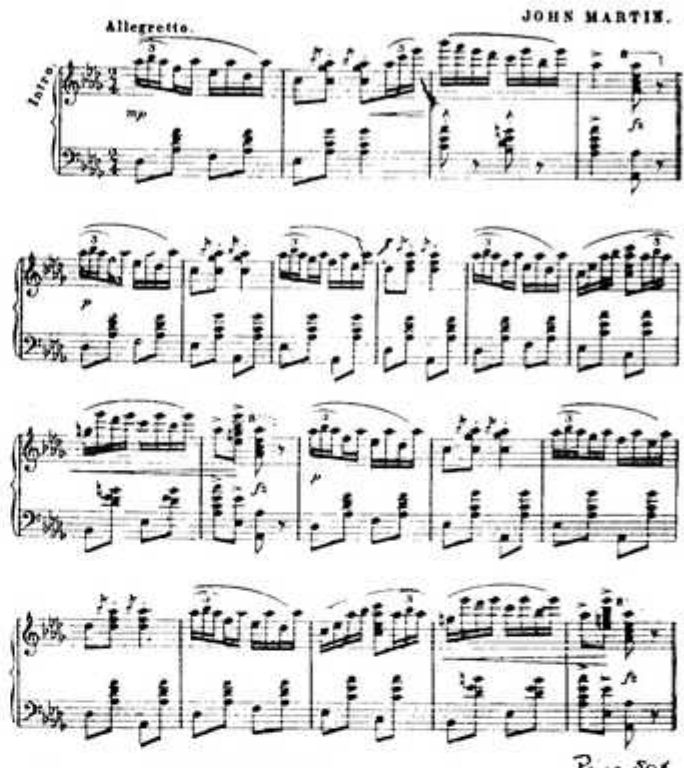

IN DREAMLAND.

heve:RIa

GEO MAYWOOD

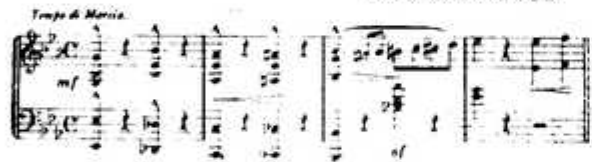

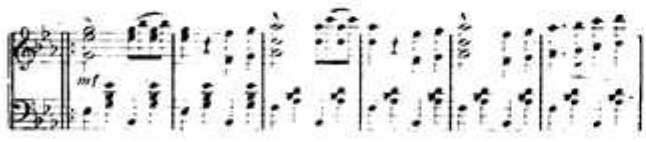

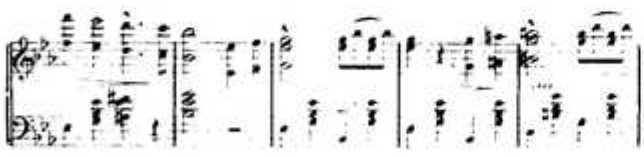

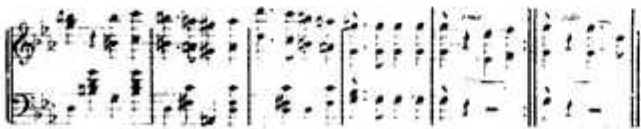

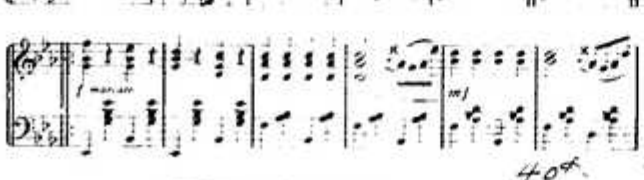
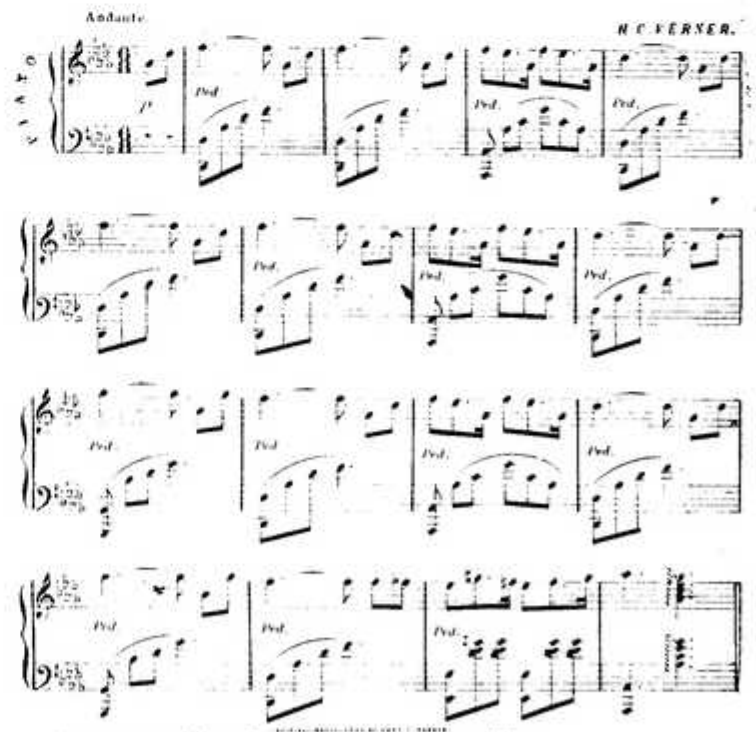

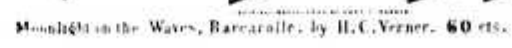

Prist $75^{4}$

FOR SALE WHEREVER MUSIC IS SOLD 